\title{
THE VALUE OF LIQUOID FOR BLOOD CULTURE
}

\author{
BY \\ R. D. STUART \\ From the Central Public Health Laboratory, Glasgow*
}

(RECEIVED FOR PUBLICATION, JULy 22, 1948)

No single medium has been devised that is suitable for the cultivation of every type of microorganism from the blood. Penfold and others (1940) confirmed the findings of Elliott (1938) on the superiority of saponin broth for the cultivation of Strep. viridans, Hoare (1939) stressed the value of trypsin liver broth in the isolation of anaerobic streptococci from patients with puerperal infections, and more fastidious organisms need even more specialized media. Although these and other recommendations can be accepted, yet the difficulties of putting the various suggestions into practice have not been sufficiently emphasized. Butler (1937) in an important monograph enumerates four different media to be inoculated at the bedside. Penfold and others, while drawing attention to Butler's relatively elaborate technique, themselves recommend four media as'a convenient range for routine work. Their methods suggest the need for considerable technical experience and - indicate the care required to avoid contamination. The difficulty of maintaining sterility in technique at the patient's bedside is considerable, and is increased by each additional manipulation. In many quarters this has led to the belief that the bacteriologist must actually withdraw the blood as well as carry out the culture. This involves waste of time, even in a hospital, and is impracticable in a public service. Again it is frequently impossible for the bacteriologist to be present at the time most favourable for blood culture. Most of the difficulties arise from the need to distribute the blood into a variety of media immediately after withdrawal. If blood could reach the laboratory in a suitable state, with the infecting organisms unharmed, these troubles would be solved. It seemed likely from the published evidence that the use of liquoid would satisfy these requirements.

Liquoid (Hoffman-La Roche) is sodium polyanethol sulphonate. It has been recognized since 1930 as a powerful anti-coagulant (Demole and Reinert). Battistini (1932) first noted that its property of inactivating complement, thus destroying the bactericidal power of human plasma, made it valuable for blood cultures. Massa and Battistini (1934) used patient's blood treated with 0.16 per cent liquoid as a self-contained culture medium, and claimed excellent results in enteric fever, meningitis, pneumonia, and septic infections. Neisner and Volencová (1934) recommended "liquoid blood" as a transport medium, and many other Continental workers supported the original claim of its usefulness in investigating bacteraemic conditions. Most of these workers used liquoid in a concentration of 0.1 to 0.2 per cent. In this country von Haebler and Miles (1938) presented experimental evidence to show that liquoid in a strength of 0.05 per cent, either alone or incorporated in broth, was excellent for blood culture, but that higher concentrations were occasionally unfavourable. Hoare in general confirmed the findings of these workers but remarked that 0.08 per cent liquoid in liver broth was experimentally inferior to trypsin liver broth for the cultivation of anaerobic streptococci. Penfold and others used liquoid broth and "liquoid blood" parallel with other media in 160 routine blood cultures, and found no evidence to suggest any advantage from their use. Most of their cultures, however, were carried out with liquoid in a final concentration of 0.17 per cent, more than three times that recommended by von Haebler and Miles.

Further information on the rationale of the use of liquoid was provided by Auxilia (1934), who pointed out that, in addition to destroying bactericidal complement, it interfered with the phagocyticactivity of leucocytes. Allgöwer (1947) went further, and showed that in experimental tissue cultures traces of liquoid completely prevented phagocytosis, and concentrations as low as 0.01 per cent exerted an obvious inhibitory effect on leucocytic migration.

Accordingly it - was decided to use liquoidtreated blood both as a transport medium and as a culture medium and to carry out routine aerobic and anaerobic cultures with small volumes of the blood on various media in addition to incubating it as a self-contained culture. At the same time the results of parallel cultures in an average "enriched" broth medium were to be compared.

\footnotetext{
*Now Bacteriology Department, Royal Infirmary, Glasgow.
} 


\section{Methods}

These were selected as suitable for the large general hospital in which this work was carried out.

Blood-culture outfit.-This consisted of a 10-oz. bottle with a perforated cap and a rubber liner, containing $100 \mathrm{ml}$. papain digest broth and $5 \mathrm{ml}$. of sheep's blood (boiled blood broth). To this was attached by a string loop a small 1-oz. (H. 53 U.G.B.) bottle with the screw cap similarly adapted containing $1 \mathrm{ml}$. of 0.3 per cent liquoid in saline. Both bottles were sterilized by autoclaving. A dry sterilized syringe and two needles were also provided.

Ward technique.-This varied according to the preference of different hospital units. The method recommended was to swab the patient's arm first with spirit-soap or ether-soap, then with surgical spirit. Approximately $10 \mathrm{ml}$. of blood was taken from the patient and the needle detached from the syringe. The second needle was then fitted to the syringe with a sterile forceps, and $5 \mathrm{ml}$. of blood was ejected into each bottle by perforating the rubber cap.

Laboratory technique.-Both bottles were incubated for 24 hours except under special circumstances ; $0.5 \mathrm{ml}$. of "liquoid blood" was then distributed by pipette to each of two tubes, one of nutrient broth, one of thioglycollate broth (Brewer, 1940). At the same time a drop of blood was spread on a blood-agar plate and another was smeared on a slide. From the ordinary blood culture bottle subcultures were made to blood agar in the usual way. This routine was rerepeated after a further 24 hours' incubation of the original bottles. Anaerobic plate cultures were carried out as required to confirm the character or establish the identity of organisms seen in films from the boiled blood broth or Brewer's medium but which failed to grow aerobically on solid media. The subcultures and original blood cultures were examined regularly and were not considered negative until after 7 days' incubation. For special examinations the "liquoid blood" was occasionally subcultured to other media, according to indication.

\section{Results}

Eight hundred and sixteen blood cultures were made, of which 170, from 141 patients, were positive. The Table shows the relative values of the methods used. The times given indicate approximately the period of incubation before subculture to a solid medium was successful. In most instances the "liquoid blood" inoculum was taken directly from the blood culture bottle, but it was occasionally taken from an early subculture in nutrient or thioglycollate broth.

In the course of this work liquoid was found to have advantages other than the maintenance of blood in a state suitable for diagnostic culture.
Sometimes measured amounts of " liquoid blood" were dispersed in poured plates for the estimation of degrees of bacteraemia, and the blood plasma obtained on standing or by centrifuging was also sometimes used for agglutination tests. Repeated examinations showed no significant difference between the agglutinin titres of serum and "liquoid plasma" from the same source. Thus it was occasionally possible to obtain a serological diagnosis by demonstrating a higher titre in a serum taken for Widal examination than in the "liquoid plasma" of an earlier blood culture. On one occasion a "liquoid blood" culture was obtained from a nurse who had been ill for one week with fever and vague pains in the joints. Four days later her serum Widal test was positive to $S$. paratyphi-B 1/5,000 (H), 1/320 (O), while the titre of the plasma from her earlier blood culture was only $1 / 640(\mathrm{H})$, negative $(\mathrm{O})$. From repeated examinations of similar specimens during periods of incubation the loss in agglutinin titre during such incubation was known to be trifling, and the rise in titre so demonstrated established the diagnosis of paratyphoid fever. It was also possible to obtain an early indication of enteric infection by serological tests on plasma from a "liquoid blood" culture and later to confirm the diagnosis by the isolation of the infecting organism from the same specimen. $S$. paratyphi-B was isolated from such a blood culture with a specific plasma titre of $1 / 3,200(\mathrm{H}), 1 / 50$ (O). By similar methods it was occasionally possible to determine the aetiological importance of organisms of doubtful pathogenicity. Thus the recovery of $B$. coli from a patient's blood became significant when the "liquoid plasma" was found to agglutinate the organism to a titre of $1 / 1,280$. On three occasions the diagnosis of Weil's disease was suggested by a positive serological test on liquoid plasma before it was clinically suspected.

\section{Discussion}

This is the largest series so far reported of blood cultures in which the use of liquoid has been compared directly with more usual methods. "Liquoid blood" has proved to be a good culture medium, but it is now suggested that liquoid is most valuable as a vehicle in which a specimen of blood can be brought to the laboratory for the bacteriologist's investigations. It can then be distributed into various culture media as considered advisable. This answers any criticism suggested by the results of Hoare or of Penfold and others, who used "liquoid blood" itself as a culture medium. Direct trial against a variety of 
other recommended culture media has not been attempted, but subculture to digest broth, Brewer's thioglycollate broth, and blood agar appears to allow successful isolation of most of the bacteria likely to be encountered in hospital practice. Penfold and others, using saponin broth, obtained eleven positive results in eleven cultures from patients with Strep. viridans infections, figures much superior to those obtained with other culture media used in parallel. In this series forty-six positive Strep. viridans cultures out of a possible total of forty-eight were obtained both from " liquoid blood" and from the enriched broth used in parallel. That the failures, one by each method, were probably due to the chance distribution of bacteria in blood specimens, is suggested by the occasional finding that in one blood culture the infecting organism might grow luxuriantly from boiled blood broth and poorly, or not at all, from liquoid, while in a further specimen from the same individual a few days later the reverse would be experienced. During this period of trial no case of subacute bacterial endocarditis due to this infection came to necropsy without a previous diagnosis by blood culture; and it is unlikely that any established Strep. viridans septicaemia remained undetected. It can therefore be assumed that for ordinary aerobic bacteria the use of "liquoid blood" for transport and subculture into the suggested media is as good as the use of other recommended media, but for certain bacteria it has advantages. In this series anaerobic streptococci, fusiform bacilli, and $F$. necrophorus were isolated more frequently from the "liquoid blood" specimen. This was undoubtedly due to the routine use of a convenient clear anaerobic fluid medium (Brewer's) for subculture. Much heavier inocula can be used than in subcultures from ordinary broth to solid media for anaerobic incubation, with the consequent greater opportunity of recovering such bacteria. Routine anaerobic incubation of subcultures to solid media is also thought in many busy laboratories to be unduly laborious. Early growth in this thioglycollate medium is much more easily seen than in Robertson's meat medium or in liver broth recommended by other workers. Again, an organism such as L. icterohaemorrhagiae can never be grown from any ordinary culture medium, yet a small amount of a "liquoid blood" specimen can readily be subcultured to a special leptospiral medium if suspicion of such an infection arises. Although leptospirae were recovered only on one occasion in this series, the general suitability of the procedure has been demonstrated by numerous isolations from the blood of infected guinea-pigs (Stuart, 1943). Since this investigation was completed Allison (1944) has also mentioned the use of liquoid as a vehicle for the transport of blood culture specimens.

TABLE

COMPARATIVE CULTURE RESULTS FROM BOILED BLOOD BROTH AND "LIQUOID BLOOD"

\begin{tabular}{|c|c|c|c|c|c|c|c|c|c|c|c|c|}
\hline \multirow{2}{*}{ Organism } & \multirow{2}{*}{$\begin{array}{c}\text { No. of } \\
\text { patients }\end{array}$} & \multirow{2}{*}{$\begin{array}{l}\text { Total. } \\
\text { no. of } \\
\text { positive } \\
\text { cultures }\end{array}$} & \multicolumn{4}{|c|}{ Boiled blood broth } & \multicolumn{4}{|c|}{ Liquoid } & \multirow{2}{*}{$\begin{array}{l}+\mathbf{B} \\
-\mathbf{L}\end{array}$} & \multirow{2}{*}{$\begin{array}{l}-\mathbf{B} \\
+\mathrm{L}\end{array}$} \\
\hline & & & $\begin{array}{c}24 \\
\text { hrs. }\end{array}$ & $\begin{array}{c}48 \\
\text { hrs. }\end{array}$ & Later & Total & $\begin{array}{c}24 \\
\text { hrs. }\end{array}$ & $\begin{array}{c}48 \\
\text { hrs. }\end{array}$ & Later & Total & & \\
\hline $\begin{array}{l}\text { Staph. pyogenes } \\
\text { Strep. pyogenes } \\
\text { Strep. viridans } \\
\text { Strep. non-haemolytic. } \\
\text { Strep. anaerobic } \\
\text { Strep. pneumoniae } \\
\text { Micrococcus Sp. } \\
\text { N. meningitidis } \\
\text { H. para-influenzae } \\
\text { S. typhi } \\
\text { S. paratyphi-B } \\
\text { S. enteritidis . . } \\
\text { B. coli .. } \\
\text { B. proteus . . } \\
\text { F. fusiformis . . } \\
\text { F. necrophorus } \\
\text { L. icterohaemorrhagiae }\end{array}$ & $\begin{array}{r}38 \\
20 \\
37 \\
4 \\
3 \\
9 \\
1 \\
1 \\
2 \\
2 \\
13 \\
1 \\
5 \\
1 \\
1 \\
2 \\
1\end{array}$ & $\begin{array}{r}42 \\
21 \\
48 \\
5 \\
3 \\
9 \\
4 \\
3 \\
3 \\
2 \\
16 \\
2 \\
6 \\
1 \\
1 \\
3 \\
1\end{array}$ & $\begin{array}{r}22 \\
19 \\
23 \\
2 \\
0 \\
8 \\
2 \\
2 \\
0 \\
0 \\
8 \\
1 \\
6 \\
1 \\
0 \\
0 \\
0\end{array}$ & $\begin{array}{r}12 \\
20 \\
0 \\
0 \\
0 \\
2 \\
1 \\
1 \\
1 \\
5 \\
0 \\
0 \\
0 \\
0 \\
1 \\
0\end{array}$ & $\begin{array}{l}3 \\
3 \\
1 \\
2 \\
0 \\
0 \\
0 \\
2 \\
1 \\
2 \\
0 \\
0 \\
0 \\
0 \\
1 \\
0\end{array}$ & $\begin{array}{r}37 \\
19 \\
46 \\
3 \\
2 \\
8 \\
4 \\
3 \\
3 \\
2 \\
15 \\
1 \\
6 \\
1 \\
0 \\
2 \\
0\end{array}$ & $\begin{array}{r}25 \\
18 \\
27 \\
2 \\
0 \\
9 \\
1 \\
2 \\
0 \\
0 \\
4 \\
0 \\
6 \\
1 \\
0 \\
0 \\
0\end{array}$ & $\begin{array}{r}11 \\
1 \\
16 \\
1 \\
2 \\
0 \\
2 \\
1 \\
1 \\
1 \\
6 \\
1 \\
0 \\
0 \\
0 \\
2 \\
0\end{array}$ & $\begin{array}{l}2 \\
0 \\
3 \\
1 \\
1 \\
0 \\
1 \\
0 \\
2 \\
0 \\
5 \\
0 \\
0 \\
0 \\
1 \\
1 \\
1\end{array}$ & $\begin{array}{r}38 \\
19 \\
46 \\
4 \\
3 \\
9 \\
4 \\
3 \\
3 \\
1 \\
15 \\
1 \\
6 \\
1 \\
1 \\
3 \\
1\end{array}$ & $\begin{array}{l}4 \\
2 \\
2 \\
1 \\
0 \\
0 \\
0 \\
0 \\
0 \\
1 \\
1 \\
1 \\
0 \\
0 \\
0 \\
0 \\
0\end{array}$ & $\begin{array}{l}5 \\
2 \\
2 \\
2 \\
1 \\
1 \\
0 \\
0 \\
0 \\
0 \\
1 \\
1 \\
0 \\
0 \\
1 \\
1 \\
1\end{array}$ \\
\hline Total & 141 & 170 & 94 & 43 & 15 & 152 & 95 & 45 & 18 & 158 & 12 & 18 \\
\hline
\end{tabular}

$+B-L=$ Positive from broth, negative from liquoid.

$-\mathbf{B}+\mathbf{L}=$ Negative from broth, positive from liquoid. 
Attention has been drawn for the first time to the use of "liquoid plasma" for agglutination tests. This allows the same specimen to be used for a Widal test as well as for culture for any likely organism. The possibility of making a serological diagnosis by the detection of a rising specific titre by retrospective examination of the plasma from an earlier blood culture is also valuable on occasion.

In general medical practice away from hospital facilities the difficulty of obtaining sterile syringes, etc., greatly reduces the practicability of using blood cultures for diagnosis. Yet the general practitioner often sees a patient at a time when blood culture is a vital diagnostic procedure. In this sphere the use of a vacuum venule is especially suitable, especially if it contains liquoid instead of the culture media more commonly employed. Some years ago a venule was marketed containing $1 \mathrm{ml}$. of 1 per cent liquoid. This was much too strong, and more recently a venule containing $1 \mathrm{ml}$. of 0.3 per cent liquoid has been introduced, which will produce a final concentration of 0.05 per cent in the average volume of $5 \mathrm{ml}$. of blood collected. This concentration has been used in the present series of cases and has proved entirely satisfactory.

Liquoid has been found useful by Fleming (1943) in determining the bactericidal power of blood after penicillin therapy, but it has been shown by May, Voureka, and Fleming (1947) to be unsuitable for the titration of streptomycin in body fluids. Its capacity to interfere with streptomycin activity may, however, prove useful in the isolation of infecting bacteria from patients under treatment with this antibiotic agent.

\section{Summary}

Liquoid (Hoffman-La Roche), in a final concentration of 0.05 per cent, has been used in blood cultures, for making a self-contained culture medium, and as a transport vehicle. The results in 816 blood cultures have been compared with those from a boiled blood-broth medium used in parallel. Of a total of 170 positive cultures, 157 were obtained from "liquoid blood," and 152 from the enriched broth medium. In a few instances fastidious bacteria were cultured with greater facility from the "liquoid blood," but its chief advantage appears to be the simplicity of its use. The taking of a single sample of a patient's blood into one container minimizes the risk of contamination, and the benefit of using a variety of culture media can be readily obtained by appropriate subcultures in the laboratory. Thus the chief value of liquoid is in transporting blood specimens to the laboratory in a suitable state for bacteriological investigation.

An unexpected advantage from the use of liquoid in keeping the blood fluid has been that the plasma can be used for agglutination tests. In the series described, "liquoid plasma" has proved suitable for Widal tests and for leptospiral and other agglutination tests. The destruction of complement by liquoid, of course, renders specimens unfit for complement fixation reactions.

A suitable concentration of liquoid in vacuum venules provides the simplest and most effective means in general practice of obtaining blood for culture.

This work was carried out between 1938 and 1943 in-the Bacteriology Department of the Royal Infirmary, Glasgow, to which due acknowledgment is hereby made. Messrs. Hoffman-La Roche are thanked for supplying $3 \mathrm{~g}$. of liquoid and for providing several references not readily available.

\section{REFERENCES}

Allgöwer, M. (1947). Schweiz. med.Wschr., 77, 40.

Allison, V. D. (1944). Pharm. J., 153, 8.

Auxilia, F. (1934). Riv. Clin. pediat., 32, 818

Battistini, G. (1932). G. Clin. med., 13, 1037

Brewer, J. H. (1940). J. Amer. med. Ass., 115, 598.

Butler, H. M. (1937). "i Blood Cultures.; London.

Demole, V., and Reinert, M. (1930). Arch. exp. Path. Pharmak., 158, 211 .

Elliott, S. D. (1938). J. Path. Bact., 46, 121.

Fleming, A. (1943). Lancet, 2, 434.

Hoare, E. D. (1939). J. Path. Bact., 48, 573.

Massa, M., and Battistini, G. (1934). Zbl. Bakt. orig., 131, 241.

May, J. R., Voureka, A. E., and Fleming, A. (1947). Brit. med. J., 1,629 .

Neisner, F.; and Volencová, V. (1934). Med. Klinik., 30, 1529.

Penfold, J. B., Goldman, J., and Fairbrother, R. W. (1940). Lancet, 1, 65 .

Stuart, R. D. (1943). "A Study of Leptospirosis in the South-West of Scotland." Thesis, Univ, Aberdeen.

Von Haebler, T., and Miles, A. A. (1938). J. Path. Bact., 46, 245. 